\title{
Formación en lenguaje desde la pandemia: reflexiones y preguntas sobre una experiencia en la educación media
}

\author{
Language Training and \\ Pandemic: Reflections and \\ Questions about a Secondary \\ Education Experience
}

\author{
A formação em línguas \\ desde a pandemia: reflexões \\ e questionamentos sobre uma \\ experiência no Ensino Médio
}

Parra Mosquera, C. (2021). Formación en lenguaje desde la pandemia: reflexiones y preguntas sobre una experiencia en la educación media. Folios, (54). https://doi.org/ 10.17227/folios.54-12333

* Doctor en Ciencias Sociales y Humanas (Pontificia Universidad Javeriana). Profesor de Humanidades, Lengua Castellana, IED Normal Superior de María (Rionegro-Antioquia). Profesor de cátedra Universidad de Antioquia, Medellín, Colombia.

Correos: carlos.parra@ensdemaria.edu.co; andres.parra@udea.edu.co

Artículo recibido $19 \cdot 08 \cdot 2020$

Artículo aprobado $28 \cdot 01 \cdot 2021$ 


\title{
Resumen
}

Este artículo de investigación se basa en una propuesta vinculada a la asignatura de Humanidades, Lengua Castellana, implementada en cinco grupos de educación media. La experiencia de sistematización que se presenta a continuación se fundamenta en tensiones constitutivas de la escuela y de la formación en lenguaje que la pandemia no solo hizo evidentes, sino que las sacó del terreno de la especulación y la elucubración académica, en tanto se convirtieron en desafíos apremiantes en el trabajo con los estudiantes desde el inicio de la pandemia. El primer fundamento de la experiencia aborda la pandemia como acontecimiento inédito en la escuela que sacudió los cimientos de la cotidianidad y de la realidad escolar. El segundo atañe a las posibilidades y límites del componente curricular y didáctico, específicamente, frente a los saberes y propósitos educativos relacionados con la percepción de la realidad, la autopercepción, la imaginación, la voluntad, el deseo, las emociones y otras dimensiones de la subjetividad que, históricamente, han sido invisibilizados o menospreciados en las tradiciones curriculares predominantes en la educación pública en Colombia. Finalmente, se presentan algunas preguntas y cuestiones a tener en cuenta para darle continuidad a una exploración de aula en relación con las metodologías y la investigación didáctica y, por supuesto, frente a los desafíos asociados a los periodos de alternancia y pospandemia.

\section{Palabras clave}

educación secundaria, pandemia, didáctica de la lengua, currículo, subjetividad

\begin{abstract}
This research article refers to a proposal based on language teaching that was implemented in five groups of secondary education. The systematization experience that is presented below is based on constitutive tensions of the school and language training that the pandemic not only made evident, as they became pressing challenges in working with students since the onset during this time. The first component addresses the pandemic as an unprecedented event at school that shook the foundations of everyday life and school reality. The second concerns the possibilities and limits of the curricular and didactic component, specifically, the knowledge and educational purposes related to the perception of reality, selfperception, imagination, will, desire, emotions and other dimensions of subjectivity. Those elements, historically, have been invisible or underestimated in the prevailing curricular traditions in the country's public education classrooms. Finally, some questions and issues to be considered are presented for continuing a classroom exploration in relation to methodologies and didactic research and, of course, the challenges associated with alternation and post-pandemic periods for language training.
\end{abstract}

\section{Keywords \\ secondary education; pandemic; language teaching; curriculum; subjectivity}

\section{Resumo}

Este artigo de pesquisa faz parte de uma proposta vinculada à disciplina de Letras, Língua Espanhola, implementada em cinco turmas do ensino médio. A experiência de sistematização que se apresenta a seguir se fundamenta nas tensões constitutivas da escola e da formação linguística que a pandemia não só evidenciou, mas também as tirou do campo da especulação e da elucubração acadêmica, na medida em que se tornaram desafios prementes no trabalho com os alunos desde 0 início deste período de pandemia. 0 primeiro alicerce da experiência aborda a pandemia como um acontecimento inédito na escola que abalou os alicerces do cotidiano e da realidade escolar. A segunda se refere às possibilidades e limites do componente curricular e didático, especificamente, contra os saberes e propósitos educacionais relacionados à percepção da realidade, autopercepção, imaginação, vontade, desejo, emoções e outras dimensões da subjetividade que, historicamente, tornaram-se invisíveis ou subestimados nas tradições curriculares prevalecentes na educação pública na Colômbia. Finalmente, apresentam-se algumas questões a ter em consideração para dar continuidade a uma exploração em sala de aula em relação às metodologias, à investigação didáctica e, claro, face aos desafios associados aos períodos de alternância e pós-pandemia.

\section{Palavras chave}

ensino médio; pandemia; didática da linguagem; currículo; subjetividade 


\section{Introducción}

El 16 de marzo de 2020 nos enviaron para la casa a los profesores, estudiantes y directivos de los colegios de Rionegro (Antioquia). Al país había llegado un virus del cual ya teníamos noticias desde semanas antes por medio de noticieros, redes sociales y diversos medios. Toda la comunidad educativa debía permanecer en casa. Los profesores del colegio estábamos aturdidos no solo por la información cambiante y acelerada sobre la situación, sino también porque debíamos planear y entregar estrategias y actividades para iniciar el trabajo escolar con los estudiantes un mes después. Durante los primeros días y hasta muy avanzado el mes de mayo, incluso junio, algunos profesores respondimos a este desafío pedagógico y didáctico con muchos titubeos y sin pretender domesticar, ni disimular la enorme incertidumbre asociada con este tiempo para la escuela. Sin embargo, fuera de la escuela, no había pasado ni siquiera un par de semanas después de iniciar la cuarentena y ya proliferaban las voces de diversos expertos académicos y funcionarios del Gobierno en simposios, seminarios y eventos, frente a la educación y la escuela en tiempos de pandemia; como si los saberes y las experiencias vinculadas con este remezón cultural para la escuela y la sociedad obedecieran a la urgencia periodística de última hora; algo parecido a una carrera para saber quién diagnostica, especula, pontifica y publica primero no solo para ganarse los créditos, sino también para brindar esa certeza y cierto consuelo que se le atribuye, con frecuencia, a la voz y autoridad del experto (así no haya pisado una escuela real en los últimos seis meses por más de tres horas). En suma, acaeció una avalancha discursiva sobre la educación y la pandemia que actuó como una suerte de primeros auxilios y paliativos para que el sinsentido, la incertidumbre y la extrañeza no desnudaran, ni amenazaran más de la cuenta, la maquinaria cultural que, rutinariamente, confecciona la normalidad del día a día en la educación regular, de manera tan cotidiana que se vuelve imperceptible la mayoría del tiempo.
Evidentemente, todo esto ha representado un acontecimiento inédito en el campo educativo escolar. Sin embargo, ante la tentación casi irresistible de hablar sobre la pandemia en la educación mediante foros, congresos, conversatorios, simposios y otros eventos que aún hoy abundan en diversas plataformas; el silencio, la escucha atenta y la observación también han sido opciones para abordar, conocer y navegar por este movimiento profundo de la escuela y de la vida en general. Conviene recalcar que este posicionamiento no es mejor, ni peor que los otros; sin embargo, ha sido la postura que ha permitido trazar una experiencia formativa gestada e implementada desde la asignatura de Humanidades, Lengua Castellana, en cinco grados de educación media en la Institución Educativa Escuela Normal Superior de María y cuya sistematización se presenta a continuación.

\section{Fundamentación de la experiencia}

La propuesta de enseñanza que da lugar a esta experiencia tiene origen en dos componentes. El primero fue el movimiento estremecedor que se produjo desde marzo de 2020 con motivo de la pandemia. La intensidad de tal remezón se debe a que sacudió los cimientos de la cotidianidad y de la realidad escolar que son, no tanto los saberes curriculares, los contenidos y las promesas pedagógicas desgastadas, sino, sobre todo, las formas de organización del tiempo, del espacio, de los objetos y de las interacciones entre profesores, estudiantes y directivos. Precisamente, todo ello derivó en una oportunidad inédita (casi ineludible) para abordar dimensiones de la subjetividad como son las emociones, las pasiones, la imaginación, el deseo y la voluntad. Las cuales, según Saenz (2001), constituyen una caja de pandora frente a la que se ha tenido una clara desconfianza y han quedado por fuera de los fines de la educación pública.

De allí la importancia de ampliar un poco más el modo en que se entendió/percibió este movimiento o remezón. Este ha sido un catalizador profundo, porque se movió abruptamente (incluso desapareció o quedó en suspenso por un momento) la 
escolarización moderna en cuanto proceso y resultado histórico de relaciones de saber/poder que se actualizan en el día a día escolar desde hace siglos. Se movieron o cambiaron formas naturalizadas que, por lo mismo, parecían inamovibles e irrenunciables. Por ejemplo, antes de la cuarentena, era casi imposible para un directivo lograr autorización de una Secretaría de Educación para desescolarizar; al inicio de la cuarentena quedaron desescolarizados los estudiantes y hasta los profesores; desapareció el uso de uniformes, los horarios escolares y el control de asistencia perdió sentido (por un tiempo) y, sobre todo, cambió la función práctica de encierro que ha cumplido la escuela para la sociedad. Recordemos que, según Saldarriaga (2003), la escuela pública moderna nace a finales del siglo XVII, con dos objetivos: mantener encerrados y durante cierto tiempo a los hijos de las clases trabajadoras y enseñarles los rudimentos del conocimiento y los hábitos necesarios para la vida civilizada, en la nueva sociedad industrial capitalista.

Entonces, ha sido un cambio histórico que se remonta a dinámicas del funcionamiento escolar que tienen raíz en el siglo xvir y que, a su vez, han servido para dar sentido y construir una percepción y agencia de la realidad escolar que, precisamente, se estremeció en marzo de 2020 de un modo inédito. La pandemia y la cuarentena han permitido y exigido reconocer que el tiempo, el espacio y la realidad (no solo escolar) están condicionados, en gran medida, por acuerdos que ratificamos cotidianamente mediante interacciones y mediaciones simbólicas que, por efecto de la reiteración, generan y alimentan hábitos, costumbres y procesos de identificación. Los cuales, además, son bastante reacios al cambio, la incertidumbre, la incoherencia, la diversidad y la singularidad. Estos últimos rasgos han sido invisibilizados, evadidos o disimulados con cierto éxito en la escuela regular, pero la pandemia funcionó como un catalizador que los exacerbó en la subjetividad de estudiantes, profesores y en la comunidad educativa en general. Esto ha sido un desafío formativo concreto e inmediato que ha exigido toda la disposición y creatividad para emprender adecuaciones curriculares que pasan, incluso, por un cuestionamiento de supuestos inamovibles hasta ahora en relación con los saberes y propósitos escolares naturalizados en la formación en lenguaje.

El segundo componente que fundamenta esta experiencia corresponde específicamente a las posibilidades y límites del componente curricular y didáctico. En particular, me refiero a los saberes y propósitos educativos relacionados con la percepción de la realidad, la autopercepción, la imaginación, la voluntad, el deseo, las emociones, la autonomía y otros aspectos asociados con dimensiones de la subjetividad que se manifestaron, inusitadamente, en estudiantes y profesores cuando se estremecieron, desde marzo, las coordenadas habituales con las que construíamos nuestra realidad escolar.

En cuanto a los saberes y los propósitos escolares, conviene recordar que la incursión, desaparición o modificación de un saber en la escuela involucra complejas lógicas y procesos históricos y sociales y, por eso, visibiliza y acentúa unos sentidos y desestima o invisibiliza otros (Parra, 2016). Además, la tradición curricular que se apropió en Colombia a mediados del siglo xx tiene su linaje más fuerte en el ámbito anglosajón. Su base teórica fue el análisis de tareas (task analysis) para orientar diversas decisiones curriculares sobre qué es importante enseñar y evaluar, para qué y cómo. Desde su estilo y tono cientificista para la época, este referente histórico (vigente de muchas maneras en la actualidad) ratificaba una división entre los fines u objetivos formativos útiles y viables y los inútiles e intratables. Esto ha tenido, evidentemente, implicaciones en cómo se valoran o no los saberes escolares y las prácticas de aula que van en una u otra dirección. Al respecto, se sugería evitar aquellos objetivos educativos que son

[...] aspiraciones y esperanzas vagas o rimbombantes. Ejemplos de esto son la formación del carácter, el desarrollo armónico del individuo, la eficiencia social, la disciplina general, la cultura, etc. Todos estos siguen siendo válidos, pero son demasiado nebulosos para servir de guías en la práctica. Pertenecen a la visionaria adolescencia de nuestra profesión; no a la prudente y un tanto desengañada madurez. (Bobbit, citado por Martínez-Boom, Noguera y Castro, 2003, p. 75) 
Según esta perspectiva, lo nebuloso es una niñería que remite a objetivos o metas educativas ostentosas y llamativas como el desarrollo armónico del individuo. Metas que no se pueden tocar, ni ver, que no se dejan controlar, predecir, ni encerrar fácilmente en los cajones acostumbrados y acostumbradores del tiempo y la planeación curricular lineal. En Colombia, por ejemplo, hay seis grandes metas de la formación en lenguaje en la educación básica y media, a saber: a) la comunicación; b) la transmisión de información; c) la representación de la realidad; d) la expresión de los sentimientos y las potencialidades estéticas; e) el ejercicio de una ciudadanía responsable, y f) el sentido de la propia existencia (Ministerio de Educación Nacional, 2006). Podríamos decir que allí hay unas metas nebulosas y otras que no lo son, o que son menos vagas y rimbombantes. Por ejemplo, es más fácil hacer indicadores y rúbricas evaluativas para las metas de comunicación y transmisión de información (por ejemplo: identifica la idea central, usa distintos conectores, reconoce el texto narrativo, etc.). Sin embargo, resulta muy difícil (casi frustrante y absurdo) cuando se intentan encajar las metas formativas más nebulosas en las casillas y los instrumentos de los indicadores; así sucede con la expresión de los sentimientos y las potencialidades estéticas; el sentido de la propia existencia o el ejercicio de una ciudadanía responsable. Tales metas concuerdan con dimensiones de la subjetividad que representan una amenaza para la moral, el orden y el progreso, como lo demostró Saénz (2001) en sus trabajos sobre la historia de la práctica pedagógica en Colombia:

La conformación de un individuo con un ámbito personal de libertad no puede presentarse en nuestro país como un logro alcanzado por la educación y la modernidad [...] es evidente el tejido hilado por la iglesia, la ciencia y la política para excluir aquellas dimensiones de la subjetividad que han considerado peligrosas para la autoridad eclesiástica, la de la razón científica y la del orden social. (p. 299)
De igual modo, podríamos asumir la expresión de los sentimientos, el sentido de la propia existencia y el ejercicio de una ciudadanía responsable como la base de cualquier proceso de motivación genuino, porque se sitúan en un terreno de conflicto cognitivo $y$ afectivo que es la base de experiencias formativas significativas cuando se logran agenciar en el aula con mediaciones didácticas concretas de trabajo ${ }^{1}$. Pero, claro, eso depende de la perspectiva didáctica y curricular, que, en este caso, no se limita a la habilidad del parafraseo de autores de moda según la filiación institucional (Kalman, Zabala, etc.), sino que incluye cuestiones epistémicas y ontológicas de gran envergadura, debido a que, calificar despectivamente saberes y propósitos escolares como nebulosos, actualiza una tensión histórica para la formación en lenguaje que condiciona nuestras decisiones curriculares cotidianas en el aula y en las instituciones. Como lo plantea Cárdenas-Páez (2007):

[...] uno de los problemas epistemológicos surgidos de la modernidad se debe a la entronización de la razón, de la ciencia, la realidad, la objetividad y la verdad como principios racionales, de los cuales nos hemos valido durante centurias, en casi todas las asignaturas, específicamente en las relacionadas con el lenguaje y la literatura [...]. Con respecto al lenguaje, el positivismo estructuralista abordó la lengua a partir de dicotomías, cuyo poder excluyente y visión formal, impidieron ver más allá de la forma [...]. En el campo de la literatura, se validaron los principios anteriores mediante la teoría y la crítica literarias y la preocupación por el comentario y el análisis de obras con descuido del sentido, la creatividad y la dimensión estética. (p. 46)

En función de lo anterior, la tradición curricular dominante para la formación en lenguaje privilegia las perspectivas disciplinares y modernas, y lo nebuloso remitiría a lo inter- y transdisciplinar, incluso

1 Como las que se detallan en tres experiencias didácticas concretas en la formación universitaria (Parra, 2019) 
a lo decolonial ${ }^{2}$. Y esto, por supuesto, ha tenido exigencias e implicaciones para el componente metodológico de la propuesta implementada con los grupos de décimo y undécimo ${ }^{3}$, así como cuestionamientos sobre la investigación en didáctica del lenguaje que buscan desmarcarla de los lenguajes, formas y mecanismos de validación de los discursos cientificistas, como se expone en el apartado final.

Conviene señalar que los dos componentes que fundamentan esta experiencia corresponden a tensiones constitutivas de la escuela y de la formación en lenguaje que la pandemia convirtió en desafíos apremiantes en el trabajo con mis estudiantes y que fueron abordados mediante la experiencia que se describe y analiza a continuación. No obstante, es oportuno referenciar también los abordajes sobre la educación en tiempos de pandemia cercanos o distantes a esta sistematización.

Es obvio que a seis meses de iniciar la primera cuarentena no se encuentran aún resultados de investigación publicados en el área de la didáctica del lenguaje en educación media. Por ende, solo se encontraron documentos de trabajo, reflexiones y lineamientos donde se reconocen, en el orden nacional, por lo menos dos tendencias. Por un lado, las reflexiones, recursos didácticos y directrices provenientes desde las entidades oficiales y organismos nacionales e internacionales, y por otro, las reflexiones desde la academia y experiencias desde la escuela en la modalidad de simposios, aunque en ningún caso se registraron textos centrados en experiencias didácticas concretas para la educación media en el área del lenguaje. Abordar a profundidad la proliferación discursiva en tiempos de pandemia es una investigación que sería oportuno

2 Una discusión al respecto de lo inter- y transdisciplinar para la formación en lenguaje se explora en relación con las pedagogías y ciudadanías planetarias (Parra, 2019)

3 En cuanto a lo metodológico, se optó por la sistematización de prácticas por las herramientas y los procedimientos que brinda esta estrategia para la recolección y análisis de la información en experiencias formativas. Adicionalmente, esta estrategia tiene un interés fundamental por escuchar las prácticas y así permitir que emerjan saberes que posibiliten re-pensar su transformación, a través de la construcción y deconstrucción continua (Pérez et al., 2013). Todo lo cual es consistente con los fundamentos de la experiencia. abordar, aunque evidentemente no es materia de este trabajo.

Ahora bien, en cuanto a la primera tendencia, se destacan la publicación y socialización en los distintos entes territoriales e instituciones de los Lineamientos para la prestación del servicio de educación en casa y en presencialidad bajo el esquema de alternancia y la implementación de prácticas de bioseguridad en la comunidad educativa y, en el mismo sentido, todas las acciones y recursos de la infraestructura gubernamental orientada a favorecer y garantizar la disponibilidad y el acceso a materiales educativos mediante sitios web, aplicaciones, radio y televisión públicas. En términos generales, esta estrategia, en alianza con el Ministerio de Salud, apunta a garantizar y orientar la administración del servicio educativo en las secretarías e instituciones (MEN-MinSalud, 2020).

Frente a la segunda tendencia reconocida en los trabajos recabados a seis meses de iniciar la pandemia, sobresalen dos grupos. En primer lugar, los provenientes de colectivos académicos universitarios y, en segundo lugar, las producciones de maestros de colegio en el marco de documentos ligados al movimiento sindical.

Una característica del primer grupo es que se ocupan de ámbitos generales, como es esperable ante la contingencia, a saber: políticas públicas; temas académicos y pedagógicos (evaluación, flexibilidad curricular, interdisciplinariedad, las TIC y la virtualidad); componentes socioemocionales y ejercicios para repensar la educación, formación docente para la contingencia, entre otros; todo ello bajo el lema de los lineamientos gubernamentales: que la educación no se detenga (Universidad de los Andes, 2020; Valencia, 2020), un mantra un tanto ingenuo, aunque tranquilizador y esperanzador, pero en todo caso menos eficaz en la educación pública en las ciudades, y ni qué decir en las ruralidades.

La perspectiva del segundo grupo también aborda cuestiones generales ligadas al sistema educativo. Los documentos generados por Fecode (2020) y por profesores de colegios públicos ligados al movimiento sindical plantean referentes académi- 
cos, pero también políticos que buscan responder, en gran medida, a los lineamientos y acciones del MEN. Allí se plantean diversas ideas, cuestionamientos y propuestas en relación con la flexibilización del currículo y las modalidades de trabajo en casa según la disponibilidad técnica; dilemas entre vida y productividad, inequidad entre educación pública y privada, dinámicas familiares y escolares, la evaluación de desempeño docente y los riesgos de la alternancia, todo ello desde una perspectiva social, económica y política. En el mismo sentido se ubica el trabajo de un colectivo de maestros que, como rasgo adicional, tiene la diversidad de temas y estilos académicos y no académicos para abordar la problemática. Justamente, destaco el texto "Y los días perdieron su identidad y el tiempo fue mutante" (Blanco, 2020, p. 44), por ser la reflexión de una maestra que, en forma de diario que no se centra en una práctica pedagógica ni área académica concreta, aunque resulta afín con la experiencia formativa que se aborda en este artículo, considera variables contextuales como la temporalidad, la espacialidad y la corporeidad. Tales aspectos, justamente son infrecuentes en el panorama descrito anteriormente, porque aluden a lo singular, contextual y en ocasiones inefable de la experiencia, en suma, algo poco atractivo para las miradas y gestos inmediatistas que predominan en la educación.

La generalización es una herramienta que favorece miradas globales que captan el conjunto, como desde un avión. Sin embargo, en el caso de la educación en tiempos de pandemia, la mirada, la palabra y el gesto generalizador se tornan escandalosamente miopes e imprecisos, porque este ha sido un tiempo $y$ espacio en el que el contexto, la singularidad y la diversidad se oponen con fuerza a cualquier regularidad o ilusión de uniformidad, incluso en un mismo grado escolar, el uniforme escolar no funciona ni física, ni simbólicamente; incluso cada institución vio exacerbada y visibilizada su enorme heterogeneidad. La cual pasa por cuestiones que van desde la infraestructura arquitectónica y tecnológica institucional y en las casas de la comunidad educativa hasta los estilos de enseñanza, prácticas pedagógicas y trayectoria académica y profesional de los docentes. Tales cuestiones, evidentemente, son determinantes para el tipo de relaciones pedagógicas en este tiempo de pandemia y, más aún, para el tiempo denominado de alternancia.

En total, la experiencia del día a día ha sido una caja negra que el paso de los días quizá deje sumergida en el fondo del mar de nuestra memoria. Por ello, resulta necesario superar la queja y la indiferencia frente al desafío que para la investigación educativa representa este acontecimiento para los profesores de colegio y, precisamente en tal sentido, resulta oportuno referenciar "La cruel pedagogía del virus". Allí Boaventura de Sousa hace una lectura general y provisional, como todas las que tienen que ver con la educación en tiempos de pandemia. Sin embargo, su mirada en cuanto a los paradigmas y a la crisis en la educación y en lo social es menos ingenua que las versiones oficiales, porque contempla factores, circunstancias y posibilidades que son ignoradas por incapacidad (o intencionalmente) por parte de las fuerzas conservadoras que sostienen, casi que a como dé lugar, el statu quo en nuestros países, comunidades, familias e incluso en lo que concierne a las fuerzas conservadoras de nuestra subjetividad. La pregunta central de De Sousa (2020): “¿qué conocimiento potencial proviene de la pandemia de coronavirus?" (p. 13), coincide con la motivación de la propuesta didáctica y reflexión de este artículo.

Lo planteado por De Sousa (2020) podríamos usarlo para resignificar y aprovechar la modalidad de la alternancia en educación para darle un sentido de alternativa, puesto que

La pandemia y la cuarentena revelan que hay alternativas posibles, que las sociedades se adaptan a nuevas formas de vida cuando es necesario y se trata del bien común. Esta situación es propicia para pensar en alternativas a las formas de vivir, producir, consumir y convivir en los primeros años del siglo xxi. En ausencia de tales alternativas, no será posible prevenir la irrupción de nuevas pandemias que, por cierto, como todo sugiere, pueden ser aún más letales que la actual. 
A corto plazo, lo más probable es que, después de que termine la cuarentena, las personas se quieran asegurar de que el mundo que conocieron no haya desaparecido. (p. 79)

\section{Descripción y análisis de la experiencia}

La propuesta que se presenta a continuación corresponde a la asignatura de Humanidades, Lengua Castellana, tuvo dos fases que se implementaron en dos grupos de grado décimo y tres de grado undécimo de la Institución Educativa Escuela Normal Superior de María, del municipio de Rionegro (Antioquia).

\section{Primera fase}

Inició el 18 de marzo con el envío de una guía de trabajo no obligatoria a los grupos de WhatsApp de los estudiantes. La conmoción que teníamos profesores, estudiantes y la comunidad educativa en general motivó la elaboración de esta guía. Mientras la escribía, yo sentía cómo se difuminaban las reglas y formas escolares que marcaban el modo en que me comunicaba y construía los encuentros con los estudiantes hasta hace unos días. A tal punto se difuminaba la cotidianidad construida en cuanto al rol de profesor, la materia de Lengua Castellana y el lugar de los estudiantes que empecé a dudar sobre la legalidad curricular de compartir esa guía con mis estudiantes, ¿qué pensarían de su profesor? Era una guía muy rara, porque era voluntaria, no se requería enviar evidencias y su tono sentimental y personal se salía de las rutinas que habíamos construido hasta ahora, ¿qué pensarían ellos o quienes la leyeran de una guía no obligatoria con un propósito tan nebuloso como lo es una invitación o una provocación que no tendría calificación? No aguanté esta extrañeza y por eso, incluí esta nota a pie en el título de la guía.

Esta guía tiene una justificación pedagógica en los principios del aprendizaje extracurricular, aunque, sobre todo, obedece a las tres últimas metas formativas que establecen los estándares de competencias para el lenguaje (MEN, 2006): la expresión de los sentimientos y las potencia- lidades estéticas; el ejercicio de una ciudadanía responsable y el sentido de la propia existencia.

Esto me servía de blindaje académico y legitimaba, de algún modo, sentirme como un intruso al mandar una tarea a los estudiantes durante sus vacaciones obligatorias (que se prolongaron desde el 15 de marzo hasta el 19 de abril); pero, sobre todo, mitigaba la sensación de extrañeza que implicaba enviar una guía sin respuesta correcta y hacerlo justo durante la vorágine de información y sensaciones que marcó los primeros días de la cuarentena.

Luego de cinco meses y a la luz de los fundamentos trazados en el apartado anterior, considero que los propósitos nebulosos (inter-transdisciplinares) en la formación en lenguaje requieren de profesores que asuman situaciones y gestos nebulosos donde es frecuente el titubeo, la duda y la extrañeza, incluso la porosidad y transitoriedad de la identidad y autoridad profesional. En efecto, se difuminan las certezas, los límites y la comodidad que ofrecen los propósitos y roles disciplinares con sus rutinas seculares; visibles en horarios y planes de área diseñados e implementados para enseñar y evaluar, casi siempre, definiciones, ejemplos y aplicaciones de las definiciones dadas de ortografía, gramática, tipologías textuales, épocas y estilos literarios. Como plantea Castro-Gómez (2013), "la disciplina ofrece una identidad profesional, un reconocimiento púbico. Aventurarse a vivir sobre los puentes [interdisciplinarios o transdisciplinarios] se toma como una pérdida, incluso como carencia y como falta de rigurosidad y cientificidad" (p. 39). Por eso, probablemente, dudé. Y decidí incluir la nota con referencias a la legislación curricular en esta guía que le envié a los estudiantes:

Guía de trabajo NO OBLIGATORIA para los grupos 10A, 10B, 11A, 11B, 11C

Tres gotitas de mocos en el aire nos han mostrado que nuestra pirámide de valores estaba invertida, que la vida siempre fue primero y que las otras cosas eran accesorios.

Empezamos a desearle el bien al vecino, necesitamos que se mantenga seguro, necesitamos que no 
se enferme, que viva mucho, que sea feliz y junto a una paranoia hervida en desinfectante, nos damos cuenta de que, si yo tengo agua y el de más allá no, mi vida está en riesgo.

Si todo sale bien, todo cambiará para siempre. Puede ser, solo es una posibilidad, que este virus nos haga más humanos y de un diluvio atroz surja un pacto nuevo, con una rama de olivo desde donde empezar de cero. (Rueda-Abrahams, 2020)

Esta es una invitación dirigida a ustedes, estudiantes y seres humanos que he alcanzado a apreciar y admirar durante este tiempo en la Escuela Normal Superior de María. Les aclaro, además, que no es obligatorio aceptar esta invitación, únicamente es de carácter voluntario.

Consiste en que ustedes creen un espacio y un tiempo para escribir lo que quieran contar sobre aquello que sienten, o sucede, durante estos días fuera de lo normal, y no solo fuera de la Normal. ATENCIÓN, si no quieren que alguien lea lo que escriben, pero sí desean escribir, también es posible, pues esto no se trata de escribir por obligación, ni para practicar el uso de la coma trabajado en clase; ni de hacerlo porque el profesor me pondrá un tres, un cuatro o un cinco, los cuales poco sirven cuando lo esencial, es decir, la vida nos está recordando otras cosas fundamentales adentro y fuera de nosotros.

Entonces, se trata de aprovechar este tiempo para que no se vaya por el sifón del televisor o algo parecido... Porque este es un tiempo que trae los más hondos aprendizajes para la vida.

Nos tocó aprender y desaprender no solo a los que supuestamente son estudiantes, menores de edad, usan uniforme y no saben, sino también a los que tienen corbata, barba, ya se graduaron, pretenden ser expertos y creían que sus respuestas para la vida eran las únicas, las correctas y que ya no tenían que aprender nada más.

Cuando digo que hay que aprovechar, es porque este es un tiempo un poco caótico $y$, por eso mismo, puede potenciar la creatividad. Esa habilidad básica no solo para pasar materias en un colegio o una universidad, sino para agradecer, apreciar y valorar más nuestra vida y menos lo que es accesorio; agradecer, apreciar y valorar, por ejemplo, la salud, la familia, el alimento, la posibilidad de hablar con otros, salir, caminar y otras acciones vitales.

En concreto, se trata de que cada uno abra un blog (en www.blogger.com), o abra un cuaderno en su casa, para escribir, cada día, pensamientos, anécdotas, poemas, cuentos, ocurrencias, sueños, canciones, parodias, sentimientos, ideas que leen o ideas que escuchan; y también para dibujar con colores o lapiceros o pegar imágenes de internet.

En resumen, los invito a crear un diario de este tiempo (usted decide si lo hace o no, si quiere compartirlo con los demás o no); quizá quieran recordar en un año, o más, lo que fue este tiempo en sus vidas, porque es muy probable que todo cambiará, de que "este virus nos haga más humanos y que de un diluvio atroz surja un pacto nuevo, con la vida, con nuestra vida".

Pueden imaginar el diario como un gimnasio o un jardin donde podremos ejercitar nuestra habilidad de observar y dibujar, cada vez con mayor colorido $y$ detalle, el paisaje interno y externo que es nuestra existencia aquí y ahora, honrando con alegría y respeto la increíble y misteriosa oportunidad de estar vivos.

Por eso mismo, la invitación no consiste en escribir abstracto, ni enredado. Tampoco es una competencia, mucho menos es una invitación a que abandonen sus hábitos o sus creencias en lo que dicen los medios de comunicación, los profesores, curas, consejeros, amigos, familiares, sobre lo que es conveniente, o no, para descifrar y recorrer el paisaje que es nuestra vida...

Quienes acepten esta invitación a escribir un diario de viaje, me lo hacen saber a mi correo del blog, y... para todos y todas... buen viaje al interior... iy buen regreso! 
Una semana después de enviar esta guía, seis estudiantes aceptaron la invitación. Una de ellas hizo un blog titulado Visita al interior'; del cual cito un fragmento:

Día \# ... No tengo ni idea cuantos días tengo en cuarentena.

Todo tiene una consecuencia, todo! Tanto lo bueno $y$ lo malo y logré verlo de esa forma porque heme aquí, a todos, encerrados, sin poder hacer todo lo nos hacia inmensamente felices pero que algunos ni nos dábamos cuenta en que medida para así protegerlo y disfrutarlo como se merecía: Abrazar, besar, reunirse con amigos... Ahora no podemos simplemente coger un bus y llegar a ese encuentro, el que hoy tanto anhelamos. Ahora el encuentro es conmigo misma en donde puedo analizar que mi conflicto interno es solo un minúsculo punto en medio de una hoja que es mi vida, en medio de un libro que es mi mundo, en medio de una biblioteca que es El MUNDO!

\section{Segunda fase}

Cuando envié la guía no esperaba ninguna respuesta de los estudiantes, sino únicamente que la leyeran. Respondieron 6 estudiantes de 180. Hice cuentas, ¿eran muchos para lo que esperaba y muy pocos para lo esperable? Esto me llevó a pensar en cómo hemos apropiado lo cuantitativo en nuestra cotidianidad del aula para valorar el éxito de nuestras acciones habituales y novedosas. No pretendo desconocer o atacar lo cuantitativo como un indicador, pero sí es vital resignificar y sospechar del valor que le damos para aprobar o descartar decisiones sobre procesos y experiencias formativas que pretenden tocar dimensiones singulares de la subjetividad $y$, por ende, reacias a la uniformidad, homogenización y la generalización en nuestras prácticas cotidianas de aula.

Entonces, al recibir seis respuestas me alegré mucho, pero intuí que otros estudiantes querían escribir o decir algo y reiteré mi provocación, mediante un cambio en la forma de la invitación.

4 Textos completos disponibles en: www.visitalinterior.blogspot.com
Este giro corresponde a la segunda fase, implementada durante la semana del 31 de marzo al 7 de abril.

De manera voluntaria y en medio de su tiempo de vacaciones obligatorias imprevistas, esta vez respondieron 66 estudiantes. La variación introducida en esta fase fue elaborar y compartir un formulario de Google titulado “¿Cómo va el viaje?”. En su presentación, el formulario retomaba la guía de la primera fase y luego tenía las siguientes preguntas:

- Pregunta 1. Datos básicos (nombres, apellidos, grupo).

- Pregunta 2. Escribir un seudónimo (con esta consigna: "Un seudónimo es un nombre falso que oculta el nombre verdadero. Usted debe escribir un nombre de una persona QUE NO SEA EL SUYO o de un objeto y que sea muy difícil (o imposible) de adivinar por parte de los demás estudiantes")

- Pregunta 3. Escriba UNA PALABRA que describa o represente cómo se ha sentido durante este tiempo. Y estas fueron las respuestas de los estudiantes:

$\begin{array}{lllll}\text { Aburrida(o) } & \text { Bien } & \text { Excelente } & \text { Loca } & \text { Reflexiva } \\ \text { agotado } & \text { Confundida } & \text { Felíz } & \text { Maaaaaal } & \text { Relajada } \\ \text { alegre } & \text { Desconectada } & \text { Frustrada } & \text { Meditación } & \text { Rutinario } \\ \text { Angustia } & \text { Desesperada } & \text { Fuerte } & \text { Normal } & \text { Saudade } \\ \text { Ansiosa } & \text { Desparchada } & \text { Haaaaaa } & \text { Paciente } & \text { Trance } \\ \text { Asombrada } & \text { Encerrada } & \text { Horrible } & \text { Pensativa } & \text { Tranquila } \\ \text { Asustada } & \text { Ensimismada } & \text { Insertidumbre } & \text { Preocupada } & \text { Triste } \\ \text { Ausente } & \text { Estresada } & \text { Interesante } & \text { Productiva } & \text { Unión }\end{array}$

- Pregunta 4. Escriba una anécdota, un sueño, un sentimiento, una reflexión o un pensamiento que usted haya tenido durante este tiempo o que haya presenciado en su casa, barrio, vereda o en los medios de comunicación.

Presento algunas respuestas firmadas con el seudónimo ${ }^{5}$.

5 Se transcriben tal cual fueron escritas por los estudiantes, las respuestas completas están disponibles en: https://receteadero.blogspot. com/p/como-va-el-viaje.html 
Al primer día de cuarentena todo empezó mal, pelea entre mis padres súper heavy, así mismo una guerra interna conmigo misma por tratar de comprenderlos pero sabiendo que ellos solo tiene una imagen superficial de mi persona y que tampoco se interesan en saber más de mi... quizás ellos han tenido varios problemas, pero esto no es razón a qué tomen un comportamiento tan repulsivo el uno contra el otro, años atrás eran la pareja perfecta que sueña con tener una familia feliz, hoy en día son todo lo que yo no quiero ser jamás! Son mi gran ejemplo de lo que no debo seguir. Es un poco nostálgico para mi recordar a mi papá como un ídolo, ahora es solo un patan que se toma el derecho y la posesión de pegarle a mi madre. (Jim)

Todo este tiempo aprendí que toda mí vida se ha basado en los estudios y realmente no se quién soy de dónde provengo ni siquiera sabía cómo era el aburrimiento en aquella casa que es mí hogar y se supone que debería ser el mejor refugio del mundo. (Ratatui)

Nunca había anhelado tanto que sonara el despertador cuando incluso sigue el cielo oscuro... Extraño la rutina qué al final no lo era tanto, extraño la fruta y el juguito empacado, el color de unos ojos especiales... Pero cada día me redescubro, y cuando voy muy de prisa me recuerdo que el tiempo y la calma están de mi lado, es raro, porque antes de toda esta locura y ahora lo sé, todo era tan rapido qué no me tomaba el tiempo para apreciar cosas qué claramente no son solo cosas. (Aguacate)

Me di cuenta que nada de lo que nos ha ofrecido la sociedad es indispensable, solo necesitamos nuestra casa, comida y a nuestra familia para estar bien, no hacen falta lujos, ropa costosa o accesorios llamativos. Estamos en nuestra casa con ropa cómoda, una coleta en el cabello, nuestra familia reunida y nada más, no necesitamos nada de lo que nos venden para ser de "mejor status" o estar a la "moda". (Morsa)

Es una situación que nunca antes había experimentado en la vida real, pero si por medio de series y películas. Personalmente, uno cree que esto jamás nos va a afectar, pero es real, es difícil de asimilar porque siempre hemos visto estás situaciones como actos fuera de nuestra vida... ¿A qué nivel va a cambiar nuestra vida, nuestra percepción sobre las cosas simples, como compartir con amigos y maestros en una linda aula? ¿Vamos a tener el mismo pensamiento ignorante $y$ decir "eso es una bobada, eso no es nada"? (Puma negro)

Estoy demasiado triste, mis relaciones interpersonales se están cayendo a pedazos, me siento acorralada, sin salida, aunque gracias a Dios mi familia está muy bien y tengo un techo para descansar. (Corazoncito)

Estas respuestas desactivaron mis artilugios y talismanes didácticos habituales; evité la tentación de echar mano de clichés o tabúes superficiales. De hecho, considero que estas respuestas de los estudiantes reclaman del profesor otras voces, mediaciones y materiales en donde, quizá haya ocasión y oportunidad (como las fisuras y las grietas en la tierra seca) para que el rol habitual del profesor y del estudiante se desdibujen y, sobre todo, muten. Evidentemente hablo de cambios y transformaciones didácticas, pero en lugar de innovaciones prefiero hablar de mutaciones, porque tienen su eje en el ámbito de las prácticas y la corporeidad, de los saberes contextuales y la cotidianidad rutinaria, de las memorias y las biografías que danzan o se agitan violentamente al sonido de una polifonía compleja de historias personales, familiares, sociales y culturales.

Las respuestas de los estudiantes lo ponen a uno como profesor de Lengua Castellana frente a senderos poco transitados no solo de su función escolar y sino incluso de su proyecto de vida. Senderos en donde no hay guías, ni mapas homogéneos, regulares, racionales, metódicos, confiables o verificables. Y si los hay, no funcionan absolutamente, pues, como plantea Saldarriaga (2003),

Hay un espacio donde la "insondable naturaleza humana", la "inasible subjetividad", la complejidad de cada persona real, escapa siempre a las estratagemas del orden y a las clasificaciones de la norma. Pero al mismo tiempo y por la misma razón, es donde se viven las tensiones [entre los procesos de disciplinamiento, normalización, 
individualización y subjetivación], en su expresión más dramática. (p. 146)

Precisamente, las respuestas de los estudiantes ejemplifican bien las dimensiones nebulosas del lenguaje y la formación que resuenan directamente con la imaginación, la voluntad, el deseo, las emociones, los afectos y otros rasgos de la subjetividad que amenazan, desbordan o pasan inadvertidas (por nebulosas) ante una mirada y práctica pedagógica disciplinar en la educación regular y en las Facultades de Educación. Estas dimensiones son la base de la formación ética, estética y política para el ejercicio de la ciudadanía, ineludible para cualquier proyecto educativo.

$\mathrm{Al}$ respecto, el primer paso es tomar conciencia de la herencia moderna y colonial sobre la ciudadanía, porque aquella se ha centrado en la "construcción del imaginario de la 'civilización' que exigía necesariamente la producción de su contraparte: el imaginario de la 'barbarie"' (Castro-Gómez, 2000, p. 3). Pero, en relación con la apertura y posibilidades que se derivan de la experiencia implementada con los grados de décimo y undécimo, lo más importante es tener en cuenta que la estrategia moderna-colonial ha tenido efectos no solo en la relación con los otros, sino en lo más íntimo de la subjetividad y los procesos de identificación de los seres humanos, pues busca como ideal de formación y de buen ciudadano "la sujeción de los instintos, el control sobre los movimientos del cuerpo, la domesticación de todo tipo de sensibilidad considerada como 'bárbara"' (Castro-Gómez, 2000, p. 3). Así pues, la acción cotidiana de estudiantes y docentes que sujetan, controlan y domestican sus instintos, su corporeidad y su sensibilidad sistemática y juiciosamente permite, obviamente, alcanzar resultados y logros inquietantes en cuanto a la formación en lenguaje; el silencio, la sordera, el mutismo y una suerte de no saber de sí. Evidentemente, esto no se queda en palabras altisonantes, bibliografías y abstracciones inofensivas; sino que corresponde a dimensiones del lenguaje y relaciones de saber-poder-ser que apuntan a la materialidad del núcleo de la subjetividad, que es la corporeidad y la cotidianidad en comunidad. Por eso se requiere de tacto pedagógico abordar esto, porque implica hacer visible una microfísica del poder (del sentir-imaginar-saber) que actúa en el interior de y entre los participantes (profesores y estudiantes). Aunque sutil o nebuloso, este ámbito de la formación es vigoroso y material, ya que "está en la base de las interacciones y sistemas de coordenadas de los sujetos y las comunidades; los afectos, las emociones, las creencias, imaginarios y otras dimensiones de la subjetividad-intersubjetividad" (Parra, 2019, p. 144). Por eso, esto constituye una tensión, un desafío y un acertijo trascendental para los maestros, en cuanto a su función de guía y acompañamiento. Al respecto, Saldarriaga (2003) plantea

[...] ¿cuál es el umbral tolerable de relación interpersonal entre el maestro y el alumno, cómo equilibrar el contacto intersubjetivo y el principio de autoridad? ¿Cuál es nivel tolerable de respeto a la intimidad y a la libertad individual y cuál el de intervención de los saberes e instrumentos sobre la interioridad, las emociones y las sensibilidades? (p. 144)

Esta cuestión es un hito importante en lo que podría ser un itinerario de investigación de aula para didácticas de lo analógico, decoloniales, inter y transdisciplinares. Investigaciones poco apetecibles para las miradas predominantes sobre investigación educativa y su red de grupos, publicaciones e instituciones, porque los plazos para evidenciar transformaciones tardan años, la sintaxis de los proyectos no cumple con la estructura que esperan los pares anónimos y, seguramente, sus resultados no serán replicables en otros contextos, por lo menos en el sentido mecánico e inmediatista en el que un maestro se forma en innovación en 120 horas.

Cuando pienso en analizar las respuestas de los estudiantes o en cómo es la aproximación que requiere una experiencia como la que se presenta en este texto y que emerge en un contexto como el trazado al inicio en relación con la pandemia, me siento perplejo y también percibo una fisura que constata que las herencias investigativas en educación han servido, en muchas ocasiones, como mordazas, 
sujetadores, controladores y domesticadores del maestro y de lo que llamamos contexto de aula o escolar 6 . Evidentemente las dos fases de la experiencia implementada señalan la importancia de considerar y, sobre todo, experimentar una ruptura o viraje epistémico esencial en cuanto a la metodología y la investigación didáctica. Indispensables para transformaciones y mutaciones de la cultura escolar y de la investigación en el aula que no obedecen únicamente a la voluntad del experto académico (sea maestro de escuela o de universidad). Esto, además, conlleva rupturas epistémicas y ontológicas de diverso orden en cuanto a los saberes y metodologías para adelantar la formación en didáctica de los maestros y la investigación didáctica como tal ${ }^{7}$, que retomo en el apartado final.

En cuanto al cierre de la segunda fase, vale decir que, luego de recibir y ordenar las respuestas de los estudiantes, las repartí aleatoriamente entre ellos y entre profesores colegas de la Licenciatura en Literatura y Lengua Castellana de la Universidad de Antioquia que quisieron participar de este intercambio. Unos y otros usaron seudónimos, porque, como se les indicó "la idea es que podamos leer lo que escriban los demás, pero no sabremos quién es el autor". La intención era que cada persona reaccionara por escrito a las respuestas de la persona asignada. Tal reacción podía ser, por ejemplo, escribirle una pregunta, un comentario, una reflexión, un consejo, unos versos de una canción o de un poema, una anécdota o una recomendación de lectura. Este fue el cierre de la propuesta implementada que da lugar a este texto. Sin embargo, conviene señalar que, a su vez, esta fase le dio apertura y posibilitó la exploración con los estudiantes de otros ejercicios de lectura, escritura y oralidad que se han imple-

6 Esto lo plantearon con agudeza Bustamante $(1999$, p. 31) y Saldarriaga (2003, pp. 299-300).

7 Como se documentó en otras experiencias formativas en el ámbito universitario (Parra, 2017), esta formación en didáctica estaría vinculada "a momentos de des-aprendizaje, des-escolarización y des-institucionalización; es decir, una inmersión en momentos de extrañeza en los que se visibilizan y naufragan los rostros que la modernidad y la colonialidad han tenido en nuestras historias personales; maneras de ser, de hablar, de percibir y de hacer" (Parra, 2019, p.145). mentado desde que iniciaron las clases en casa $^{8}$ y se caracterizan por apuntarle a los terrenos analógicos, inter- y transdisciplinares para la formación en lenguaje.

\section{Apartado final: un itinerario de viaje}

Lo que podríamos catalogar como las conclusiones de la experiencia presentada son, en realidad, postales hechas de posibilidades, preguntas y desafíos que forman parte de un viaje o expedición pedagógica en curso. Sin embargo, podemos perfilar dos aspectos preliminares.

El primero concierne a lo metodológico y a la investigación didáctica. Una primera cuestión que motiva la continuidad de este viaje se funda en la duda por cuáles son lenguajes y metodologías que se consideran válidos para expresar los saberes que emergen en la escuela desde la pandemia. Al respecto, una pregunta: ¿Las respuestas de los estudiantes son material relevante para la investigación didáctica? Sí, pero sería absurdo usar los datos de la experiencia con las formas calcadas de la investigación en ciencias exactas o en ciencias sociales; en donde el profesor investigador se comporta como experto o intelectual de la pedagogía, hasta donde lo permite la evidente división del trabajo que existe entre colegios y universidades. Ahora bien, ¿las respuestas de los estudiantes son material relevante para una formación integral en lenguaje, que apunta, fundamentalmente, a las tres metas formativas de los estándares que atañen a la expresión de los sentimientos y las potencialidades estéticas; el ejercicio de una ciudadanía responsable y el sentido de la propia existencia? (MEN, 2006). Considero que la respuesta también es afirmativa. Estas metas y las posibilidades que ofrecen las perspectivas analógicas, inter- $y$ transdisciplinares para la didáctica del lenguaje configuran un inspirador y bello horizonte que, hay que reconocerlo, tiene el riesgo de convertirse en un afiche estático y plano,

8 El trabajo con el lenguaje audiovisual como detonador de la oralidad y la escritura ha sido central, mediante el uso de materiales como videoclips, canciones, memes y la lectura y escritura de textos cortos. 
un decorado animado únicamente en congresos, seminarios, proyectos universitarios y publicaciones indexadas.

Ante tal riesgo hay alternativas (lenguajes y herramientas) para darle vida a ese horizonte en las aulas. En primer lugar, se requiere considerar una ruptura epistémica y ontológica desde la cual se entienda que moverse hacia el horizonte formativo del sentido de la propia existencia, de la expresión de los sentimientos y las potencialidades estéticas y del ejercicio de una ciudadanía responsable, representa, para el maestro, estar dispuesto a desbaratarse y a desarrollar el tacto para aprender a abrir esa caja de pandora atinente a las dimensiones del lenguaje y de la subjetividad reacias al orden, la certeza y la uniformidad; y esto, evidentemente, es un trabajo de filigrana y artesanía. De allí la importancia de ponderar las posibilidades y límites de la investigación basada en artes en educación y de las miradas y aproximaciones a las estéticas no canónicas para la formación de maestros.

El segundo aspecto clave que configura el itinerario de viaje remite a las adecuaciones curriculares referidas a los saberes y los propósitos escolares tanto para acompañar a los estudiantes durante este año; así como para transitar, ojalá como experiencia formativa e investigativa, el remezón adicional que significará la llamada alternancia y la pospandemia para la educación pública. Probablemente, tanto estudiantes como profesores llegaremos con una sensibilidad singular que no podemos ignorar por el afán de instalar, forzadamente, nuestras rutinas escolares previas a la pandemia; tampoco se trata de asumir el retorno desde un lugar de atención psicológica que no nos corresponde en el sentido disciplinar y moderno asociado a tal profesión. ¿Acaso haremos caso omiso del remezón cultural acaecido en la escuela con motivo de la pandemia o podrá aprovecharse, sin amarillismo académico, la oportunidad inédita que transitamos para, como profesores, tomar conciencia de las posibilidades $y$ límites de abordar propósitos formativos y dimensiones del lenguaje que ahora no solo resultan pertinentes, sino que la situación actual requiere su abordaje y comprensión??.

Frente a esto último conviene enfatizar que la expresión de los sentimientos y las potencialidades estéticas; el ejercicio de una ciudadanía responsable y el sentido de la propia existencia (MEN, 2006), en lugar de nebulosas, son metas formativas terrígenas, corporales y orientadoras de las prácticas culturales y procesos de identificación que están en la base de todas las interacciones cotidianas y de frente a los dispositivos de poder más arrasadores. De allí la importancia de explorar las posibilidades de una perspectiva curricular y didáctica orientada a lo analógico, lo decolonial, lo inter- $y$ transdisciplinar. Tales metas resultan nebulosas para algunos porque son sutiles e imperceptibles, por efecto de la costumbre y los procesos de normalización, pero se manifiestan en prácticas concretas de aula, a saber: qué contenidos se incluyen en la planeación, cómo usar y distribuir el tiempo y el espacio de aula, el uso de la palabra, el manejo del poder.

Se trata entonces de explorar y pulir tales prácticas y decisiones de aula (ojalá como colectivo de maestros), porque forman parte, por un lado, de lo que sería una flexibilización genuina del currículo $y$, por otro, remiten a un estilo de enseñanza que, precisamente, le daría cuerpo y sentido a esas metas nebulosas. Una alternativa es crear esas formas, prácticas y maneras de decir en un sentido particular de la innovación didáctica que estremezca (o resignifique en un sentido profundo y radical, más allá del cambio de autores y bibliografías) las tradiciones escolares y culturales de las que hemos bebido para identificarnos y darle sentido a lo que hacemos. Evidentemente, este desaprendizaje o autocrítica radical se centra en la formación inicial y continua de maestros, particularmente en el componente curricular y didáctico. $\mathrm{Al}$ respecto, se encuentran elementos valiosos en la invitación que

9 Por ejemplo, los meses de encierro para los estudiantes han facilitado comprender que la palabra libertad no es únicamente un sonido o conjunto de letras impresas cuando aparece en las discusiones o lecturas realizadas en clase. 
hace el profesor Cárdenas-Páez (2007) a construir una didáctica de lo analógico,

La cuestión pedagógica ha privilegiado la racionalidad lógica, postura que riñe con la educación holística y con la posibilidad de entender al estudiante como sujeto apurado por la intersubjetividad. Parte de la solución está, entonces, en recuperar esa otra mitad: la racionalidad analógica, simbólica e imaginaria del hombre. (p. 46)

Tal vez, lo nebuloso coincide con lo analógico, es decir, alude a una dimensión del lenguaje y de la subjetividad que la pandemia vino a estremecer abruptamente; una dimensión analógica que se ha invisibilizado o desestimado históricamente en nuestras escuelas y facultades de Educación porque es incómoda, difícil, conflictiva o incluso por simple conveniencia.

La analogía, como forma de la comprensión que incorpora facetas de la sensibilidad, la imaginación y rasgos del intelecto humano, tiene en la imagen su forma privilegiada, lo que supone conocer a través de la emoción y del afecto, comprensión a mitad de camino entre la diferencia y la semejanza, entre la identidad y la diversidad [...] perfila las bases del asombro, a distancia del hábito, de la expectativa, de la norma. Cuando rebasamos el molde convencional, cuando desbordamos la costumbre, aparece la sorpresa, perdemos la confianza, nos volvemos creativos. Es, entonces, cuando captamos de manera íntegra, repentina e iluminada relaciones y cualidades entre elementos que, de continuo, participan en el campo-cuerpo/mente/cultura-de la experiencia. [...] La analogía es una manera de trabajar a partir de la vivencia, de la posibilidad que tiene cada cual de generar diversas formas de pensamiento, de sus afectos, y sentimientos, de marcar diferencias y nuevos territorios, de darse cuenta en qué se es diferente de los demás, cuáles respuestas son idiosincrásicas, cuáles se comparten con los demás, cómo vivir las propias fantasías, cómo implicarse personalmente en ellas, cómo poner mente y sentidos, cuerpo y alma, sensibilidad, imaginación e inteligencia en función de aprendizaje, cómo involucrarse personalmente en proyectos que le den sentido a la vida. (Cárdenas-Páez, 2007, pp.

47-53)

Nuestras prácticas pedagógicas heredan día a día las formas acostumbradas que privilegian ciertos saberes y evitan objetivos nebulosos y terrenos analógicos a tal punto que muchos olvidamos que existían y cómo transitarlos; tanto así que aparecen brillantemente en los estándares básicos de competencias, pero pierden color y sentido a medida que nos acercamos al aula cotidiana para que germinen $y$, entonces, resulta un trabajo infértil y castrante. La lógica de la cultura escolar que destierra sistemáticamente dimensiones de la subjetividad (como la imaginación, el deseo y las pasiones que podrían catalogarse como nebulosas) es sofisticada, pues disimula el artificio histórico y autobiográfico del que somos cómplices. Sin embargo, este tiempo de cataclismo y catálisis, también ofrece la oportunidad de visibilizar y resignificar, con tacto, nuestras prácticas y nuestra realidad escolar.

\section{Referencias}

Blanco, J. (comp.). (2020). Sopa de menudencias. Pensamiento crítico pedagógico en tiempos de pandemia. http://www.idep.edu.co/sites/default/files/ sopademenudencias $\% 20 \% 281 \% 29$.pdf

Bustamante, G. (1999). Algunos elementos para pensar la investigación educativa. Pedagogía y Saberes, 13, 31-36

Cárdenas-Páez, A. (2007). Hacia una didáctica de lo analógico: lenguaje y literatura. Pedagogía y Saberes, 27, 45-54.

Castro-Gómez, S. (2000). Ciencias sociales, violencia epistémica y el problema de la "invención del otro". En E. Lander (comp.), La colonialidad del saber: eurocentrismo y ciencias sociales. Perspectivas latinoamericanas. Consejo Latinoamericano de Ciencias Sociales (Clacso). http://bibliotecavirtual.clacso.org. ar/ar/libros/lander/castro.rtf

Castro-Gómez, S. (2013). Desafíos de la inter- y la transdisciplinariedad para la Universidad en Colombia. Trans-pasando Fronteras, 3, 33-45.

De Sousa, B. (2020). La cruel pedagogía del virus Clacso.

Federación Colombiana de Trabajadores de la Educación (Fecode) (2020). Emergencia educativa en tiempos 
del Covid-19 - Documentos de trabajo. https:// www.fecode.edu.co/images/comunicados/2020/ Documentos_de_trabajo._Emergencia_Educativa_ en_Tiempos_del_Covid-19.pdf

Martínez-Boom, A., Noguera, C. y Castro, J. (2003). Currículo y modernización. Cuatro décadas de educación en Colombia. Cooperativa Editorial MagisterioUniversidad Pedagógica Nacional.

Ministerio de Educación Nacional (MEN). (2006). Estándares básicos de competencias en lenguaje. http://www.mineducacion.gov. co/cvn/1665/article-116042.html

Ministerio de Educación Nacional (MEN). y Ministerio de Salud y Protección Social (MinSalud). (2020). Lineamientos para la prestación del servicio de educación en casa y en presencialidad bajo el esquema de alternancia y la implementación de prácticas de bioseguridad en la comunidad educativa. https:// www.mineducacion.gov.co/1759/articles-399094_ recurso_1.pdf

Parra, C. (2016). La escolarización de los saberes: un escenario relevante para rastrear y comprender algunos problemas sociales y humanos contemporáneos. Magis, Revista Internacional de Investigación en Educación, 8(17), 179-186.

Parra, C. (2017). Crisis de las humanidades y relación ser humano/naturaleza: una experiencia en la formación de maestros de lengua y literatura. Enunciación, 22(2), 217-230.

Parra, C. (2019). MediAcciones didácticas, lenguajes y transdisciplinariedad: ciudadanías planetarias en la formación universitaria. Nómadas, 49, 137-153.
Pérez, M., Roa C., Villegas, L. y Vargas, A. (2013). Escribir las prácticas: una propuesta metodológica para planear, analizar, sistematizar y publicar el trabajo didáctico que se realiza en las aulas. Pontificia Universidad Javeriana.

Rueda-Abrahams, E. (14 de marzo de 2020). Lo más lindo que he leído sobre esta pandemia: Empatía Viral. ElCronista.co. https://www.elcronista.co/ actualidad/lo-mas-lindo-que-he-leido-sobre-esta-pandemia-empatia-viral $\% 20$

Saénz, J. (2001). Emociones, pasiones e imaginación: los adversarios de la moral, el orden y el progreso. En A. Echeverri (ed.), Encuentros pedagógicos transculturales: desarrollo comparado de las conceptualizaciones y experiencias pedagógicas en Colombia y Alemania (pp. 299-310). Universidad de Antioquia.

Saldarriaga, O. (2003). Del oficio de maestro. Prácticas $y$ teorías de la pedagogía moderna en Colombia. Magisterio.

Universidad de los Andes. (2020). Educación y covid-19. Aproximaciones académicas de estudiantes y profesores de la Facultad de Educación de la Universidad de los Andes. https://educacion.uniandes.edu.co/index. php/educacion-covid

Valencia, W. (2020). Mirada a las prácticas educativas y pedagógicas en tiempos de pandemia. (Documento de trabajo). Universidad Católica de Oriente. https://www.uco.edu.co/REDPPI/ BiblioRedppi/MIRADA \% 20A \% 20LAS\% 20 PR\%C3\%81CTICAS\%20EDUCATIVAS\%20Y\%20 PEDAG\%C3\%93GICAS\%20EN\%20TIEMPOS\%20 DE\%20PANDEMIA.pdf 